\title{
Influence of Water Quality on the Variation Patterns of the Communities of Benthic Macroinvertebrates in the Lakes of the Central Highlands of Peru
}

\author{
María Custodio $^{1 *}$, Richard Peñaloza ${ }^{2}$ \\ ${ }^{1}$ Universidad Nacional del Centro del Perú, Huancayo, Perú \\ ${ }^{2}$ Universidad Nacional Agraria La Molina, Lima, Perú \\ Email: *mcustodio@uncp.edu.pe
}

How to cite this paper: Custodio, M. and Peñaloza, R. (2019) Influence of Water Quality on the Variation Patterns of the Communities of Benthic Macroinvertebrates in the Lakes of the Central Highlands of Peru. Open Journal of Marine Science, 9, 1-17.

https://doi.org/10.4236/ojms.2019.91001

Received: November 19, 2018

Accepted: January 13, 2019

Published: January 16, 2019

Copyright (c) 2019 by author(s) and Scientific Research Publishing Inc. This work is licensed under the Creative Commons Attribution International License (CC BY 4.0).

http://creativecommons.org/licenses/by/4.0/

\begin{abstract}
The influence of water quality on the variation patters of benthic macroinvertebrate communities in the lakes in the central highlands of Peru was evaluated. Samples of water and sediments were collected in 23 different sampling sites last 2017. The physiochemical variables of water quality determined on site were: DO, TDS, EC, temperature and $\mathrm{pH}$. The results obtained revealed that the physiochemical indicators are within the environmental quality standards for water, except $\mathrm{COD}$ and $\mathrm{BOD}_{5}$. Regarding the benthic macroinvertebrates, four phyla were identified wherein the most common is the phylum Arthropoda having the abundance and richness of taxa. The PCA reduced the variables to a few significant components that caused variation in water quality between lakes. The cluster analysis in relation to the relative abundance of benthic macroinvertibrates grouped the 22 sampling sites into three groups with the similar characteristics. The PCoA analysis of the benthic macroinvertebrate communities showed a clear separation of sites. The SIMPER analysis at the family-level showed the distribution of the most common species. Therefore, at a significance level of 0.01 it demonstrates that there are significant differences between the number of species and abundance of the areas that were evaluated.
\end{abstract}

\section{Keywords}

High Andean Wetlands, Water Quality, Benthic Macroinvertebrates, Diversity 


\section{Introduction}

The growing shortage of water resources and their impact of the functioning of ecosystems, make water one of the main objects of environmental protection [1]. The preservation of the integrity of aquatic environment implies conserving the physical, chemical and biological quality of water, since it influences the abundance and specific diversity of biological communities [2] [3]. However, despite of the fact that freshwater ecosystems are among the most important in the world, due to the multiple benefits and services they provide, anthropogenic activities have continued to exert strong pressure on these ecosystems, causing environmental impacts with negative [4].

In many developing countries, the use of water resources faces socio-environmental conflicts due to the growing deterioration that aquatic ecosystems are experiencing [5]. In Peru, the situation is similar, although it is a country with a strategic location for hydrological freshwater (it owns $71 \%$ of the tropical glaciers of South America, 25\% of the aquatic ecosystems in the Amazon region and its watershed represents $5 \%$ of the world's fresh water) [6]; water pollution is one of the biggest environmental problems, due to the rapid growth of the country's urban centers. The degradation of water quality is reflected in the changes in the composition of the biological communities and the loss of biodiversity that aquatic ecosystems harbor [7] [8].

Currently, new tools are being generated to evaluate the state in which continental aquatic ecosystems are found, in order to reduce the intrinsic uncertainties and subjectivities of the environmental problems that will be experiencing [9], to provide information on the historical status of a body of water and not only at the time of sampling, but also development of the multimetric indices using bioindicators [10]. Among the bioindicators the most frequently used in the evaluation of water quality are the macroinvertebrate and algae benthic communities, since they have a wide geographical distribution and response quickly to the environmental changes [11]. This study is focused spatially, in lakes that come bearing direct and indirect pressures due to the development of diverse anthropogenic activities, such as: the culture of fish (trout farming), tourism (boat-riding for recreational purposes and bird watching), livestock, agricultural activity, trade and discharges of wastewater from the human settlements located in its surroundings. In view of this, and considering the high uncertainty of the current state of these ecosystems, the objective of the study is to evaluate the influence of water quality on the variation patterns of the benthic macro invertebrate communities in the lakes of the central highlands of Peru.

\section{Methodology}

\subsection{Description of the Study}

The watershed of the Mantaro River is located in the central highlands of Peru, between, $10^{\circ} 39^{\prime}$ and $13^{\circ} 30^{\prime}$ South latitude and between $74^{\circ} 00^{\prime}$ and $76^{\circ} 30^{\prime}$ West longitude, with altitudes ranging between 500 to 5350 meters above sea level. It 
covers an area of approximately $34550.08 \mathrm{~km}^{2}$ and forms part of the slope of the Atlantic Ocean, covering the provinces of Pasco, Junin, Huancavelica and Ayacucho. The Mantaro River originates in Lake Junin and flows 735 kilometers to its confluence with the Apurimac River. As a result, the study area has a very frigid climate with an average annual temperature above $0^{\circ} \mathrm{C}$ and below $7^{\circ} \mathrm{C}$, a maximum temperature of $15^{\circ} \mathrm{C}$ and a minimum temperature of $9^{\circ} \mathrm{C}$. It has an annual rainfall of $920 \mathrm{~mm}$ with violent thunderstorms. Its flow depends on rainfall throughout the watershed, the level of the Lake Junin and the lakes located at the foot of the mountains in the western mountain ranges and the snowy Huaytapallana. The lakes that are included in this study are: Pomacocha (Pc), Tragadero (Tg), Cuncancocha (Cc), Incacocha (Ic) and Ñahuinpuquio (Ñn) (Figure 1); two of which are located in urban areas with high commercial and tourist activities; the other three have been used for the cultivation of Oncorhynchus mykiss.

\subsection{Collection and Analysis of the Samples}

Water sampling was carried out in five lakes of the central highlands of Peru, on 2017. In each lake, 23 sampling sites were defined and each of them were determined in situ: dissolved oxygen $(\mathrm{mg} / \mathrm{L})$, total dissolved solids $(\mathrm{mg} / \mathrm{L})$, conductivity $(\mu \mathrm{S} / \mathrm{cm})$, temperature $\left({ }^{\circ} \mathrm{C}\right)$ and $\mathrm{pH}$, using Hanna Instruments multiparameter probes (HI 991301 Microprocessor pH/temperature, HI 9835 Microprocessor Conductivity/TDS and HI 9146 Microprocessor dissolved oxygen), previously, the equipment was calibrated at the respective sampling site. Also, 1L of water from a depth of $20 \mathrm{~cm}$ was also collected from each sampling site for bacteriological analysis and analysis of nitrates, total phosphorus, $\mathrm{COD}$ and $\mathrm{BOD}_{5}$, in containers previously mixed with a hydrochloric acid solution in proportion 1:1 and rinsed with distilled water. The measurements of these parameters were carried out according to the standard methods [12].

The collection of sediments to obtain benthic macroinvertebrates was carried out at the sites defined by Ekman-Birge dredger from Hydro-Bios. At each sampling site, four sediment samples were taken. Then, $5 \%$ formaldehyde was added to each of the samples for preservation and subsequent observation and identification in the laboratory. The taxonomic identification of the benthic macroinvertebrates was carried out at the family level through a trinocular stereomicroscope, as they occur in the bioevaluation studies of freshwater ecosystems [13].

\subsection{Statistic Analysis}

The analysis of the physicochemical variables of the water and the benthic macro invertebrate communities were analyzed using the software PRIMER-E v7 and MINITAB v 18. Because of the anthropogenic intervention in the evaluated lakes can affect the distribution of benthic macroinvertebrate communities, the physicochemical variables of the water were analyzed according to the standard of principal components analysis (PCA) in order to generate two-dimensional 


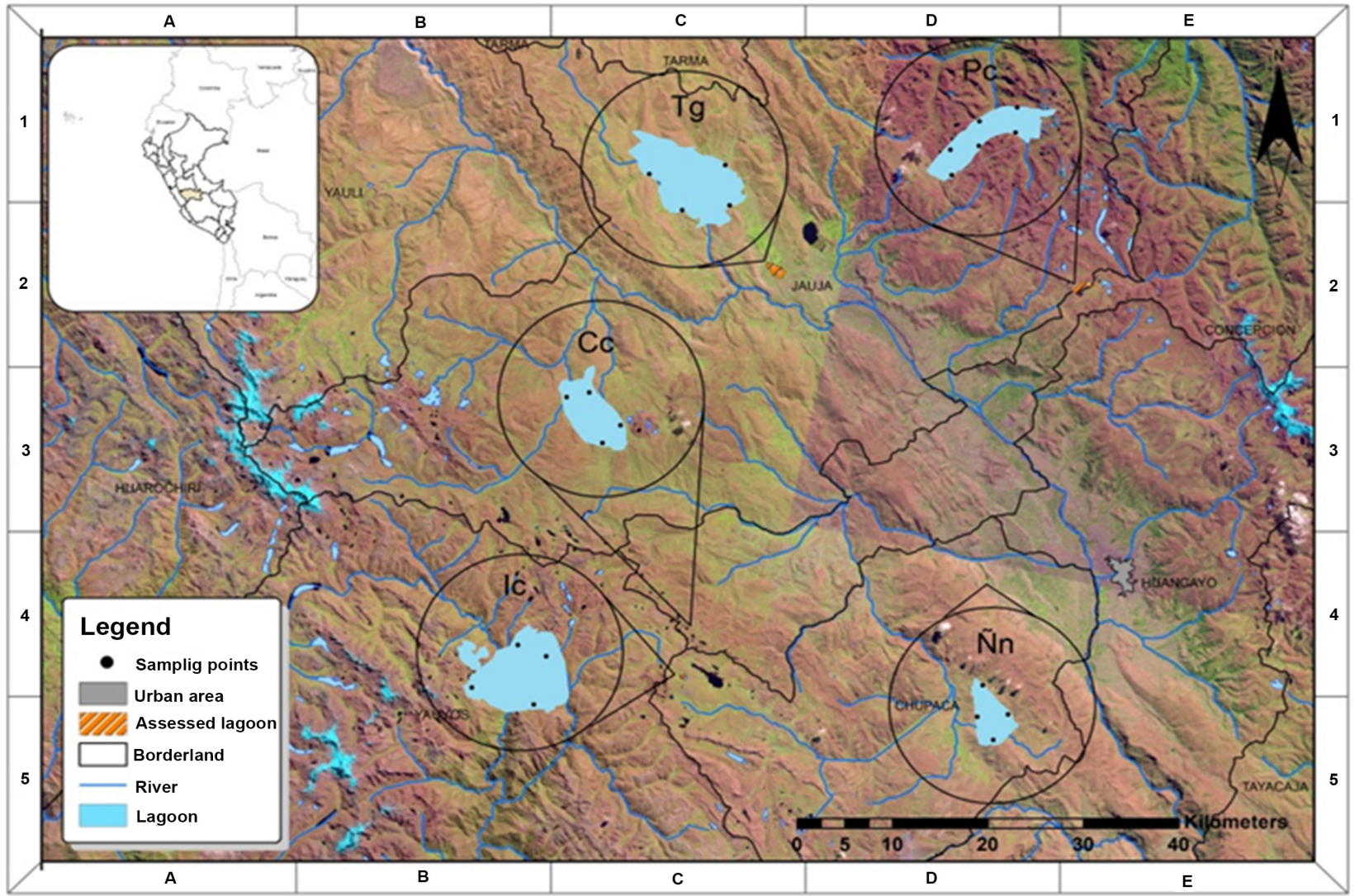

Figure 1. Location of the zones and sampling points of the evaluated lakes.

management maps [14] and look for linear relationship of better adjustment according to the calculated PC, successively maximizing the variance. To obtain the level of significance the PERMANOVA test was used according to the factor determined by the cluster analysis.

In the cluster analysis of benthic macro invertebrate communities, a hierarchical and agglomerative classification was performed, generating a similarity matrix with Bray-Curtis indices base on an abundance matrix of transformed species by square root in order to produce a dendrogram [15]. Principal coordinate analysis (PCoA) was also carried out to produce an ordinal figure [16]. The statistical significance of the generated clusters was then tested using Permutational Multivariate Analysis of Variance (PERMANOVA) [17]. Each significant association of species, resulting from the multivariate analysis, was characterized by its number of species $(S)$, number of individuals $(N)$, for counted method. The diversity was calculating whit:

- Shannon diversity index $(H)$, as follow: $H^{\prime}=-\sum_{i=1}^{S} p_{i} \log _{2} p_{i}$, where $p_{i}$ is the proportion of characters belonging to the $i$ th type of letter in the string of interest. In ecology, $p_{i}$ is often the proportion of individuals belonging to the th species in the dataset of interest.

- Margalef diversity index (d) using for calculate the species richness; $d=(S-1) / \log (N)$; where $s$ is the number of species present, and $N$ is the 
total number of individuals found (belonging to all species). The notation Ln denotes the Neperian logarithm of a number.

- Simpson index $(1-\lambda)$ for measure the degree of concentration when individuals are classified into types, $1-\lambda=1-\sum_{i=1}^{R} p_{i}^{2}$; where $R$ is richness (the total number of types in the dataset). The equation is also equal to the weighted arithmetic mean of the proportional abundances $p_{i}$ of the types of interest, with the proportional abundances themselves being used as the weights.

The main indicator species and the associated percentage of indication were determined for each significant set of species using the similarity percentage (SIMPER) [18].

The BIOENV analysis [14] was used to identify which physicochemical variables of water explains the differences in the distribution of benthic macro invertebrate communities. The relative importance of each physicochemical variable in the accounting of the variation of the communities was determined by direct selection using the DISTLM [19], according to the Akaike information criteria and step by step selection to obtain a pseudo value $\mathrm{F}$, which is a measure of the importance of the general analysis of the predictor variables. In addition, the distance-based redundancy analysis (dbRDA) was carried out, which is a restricted ordering method, to find out which are the best explanatory variables, and which axes are significant [20]. The canonical correspondence analysis (CCA) was used to evaluate the relationship between the composition of macroinvertebrates and physicochemical variables.

\section{Results}

\subsection{Water Quality Based on Physicochemical Indicators}

Table 1 shows the mean and standard deviation of the physicochemical indicators of water quality in high Andean lakes. The average $\mathrm{pH}$ of the water ranged from 6.84 in the Pc Lake to 8.61 in Ic Lakes. The highest electrical conductivity was recorded in the $\mathrm{Tg}$ Lake with an average of $269.81 \mu \mathrm{S} / \mathrm{cm}$. The average chemical demand-COD in the Tg and Cc lakes were higher than the water quality standards of Peru, category $3(40 \mathrm{mg} / \mathrm{L})$. While the biochemical oxygen demand-BOD registered in all the lakes evaluated exceeded the water quality standards of Peru, category $4(5 \mathrm{mg} / \mathrm{L})$. The lowest dissolved oxygen concentrations-DO was recorded in the Tg Lake. The average temperature ranged between $10.6^{\circ} \mathrm{C}$ in the $\tilde{\mathrm{N}}$ Lake and $17.70^{\circ} \mathrm{C}$ in Tg Lake. The total dissolved solids-TDS showed an average from $2.58 \mathrm{mg} / \mathrm{L}$ in the Cc Lake to $9.20 \mathrm{mg} / \mathrm{L}$ in Tg Lake. The average total phosphorus, nitrates iron and copper did not exceed to the Ministry of the Environment of Peru's water quality standards for lakes.

In Figure 2, the result of the principal component analysis (PCA) of the physicochemical indicators and the sampling sites of the evaluated lakes are shown. The first two components explain $77 \%$ of the total variability. The first component 
Table 1. Average and standard deviation of water quality indicators in 22 sampling sites of high Andean lakes (Pc: Pomacocha, Tg: Tragadero, Cc: Cuncancocha, Ic: Incacocha, Nn: Ñahuinpuquio).

\begin{tabular}{cccccc}
\hline Indicator & Pc & Tg & Cc & Ic & Nn \\
\hline $\mathrm{pH}$ & $6.84 \pm 0.13$ & $7.56 \pm 0.42$ & $7.16 \pm 0.25$ & $8.61 \pm 0.19$ & $7.63 \pm 0.06$ \\
EC $(\mu \mathrm{S} / \mathrm{cm})$ & $254.24 \pm 3.03$ & $269.81 \pm 7.50$ & $260.35 \pm 4.39$ & $262.53 \pm 4.02$ & $258.77 \pm 4.04$ \\
COD $(\mathrm{mg} / \mathrm{L})$ & $31.09 \pm 0.92$ & $59.64 \pm 0.23$ & $46.88 \pm 1.25$ & $38.83 \pm 0.31$ & $34.52 \pm 0.40$ \\
BOD $(\mathrm{mg} / \mathrm{L})$ & $18.07 \pm 0.39$ & $28.81 \pm 0.68$ & $18.68 \pm 0.87$ & $18.51 \pm 0.37$ & $20.80 \pm 0.40$ \\
DO $(\mathrm{mg} / \mathrm{L})$ & $6.68 \pm 0.11$ & $6.12 \pm 0.07$ & $6.49 \pm 0.16$ & $6.43 \pm 0.05$ & $7.12 \pm 0.08$ \\
Temperature $\left({ }^{\circ} \mathrm{C}\right)$ & $11.74 \pm 0.78$ & $17.70 \pm 0.16$ & $11.38 \pm 0.35$ & $10.51 \pm 0.41$ & $10.61 \pm 0.37$ \\
TDS $(\mathrm{mg} / \mathrm{L})$ & $3.09 \pm 0.07$ & $9.20 \pm 1.39$ & $2.58 \pm 0.07$ & $2.63 \pm 0.0 .19$ & $2.75 \pm 0.06$ \\
Total phosphorus & $0.042 \pm 0.006$ & $1.519 \pm 0.036$ & $0.802 \pm 0.019$ & $0.500 \pm 0.038$ & $0.740 \pm 0.008$ \\
$(\mathrm{mg} / \mathrm{L})$ & & & & & \\
Nitrates $(\mathrm{mg} / \mathrm{L})$ & $0.396 \pm 0.023$ & $0.768 \pm 0.029$ & $0.466 \pm 0.003$ & $1.506 \pm 0.023$ & $1.555 \pm 0.037$ \\
Total iron $(\mathrm{mg} / \mathrm{L})$ & $0.034 \pm 0.001$ & $0.044 \pm 0.000$ & $0.033 \pm 0.000$ & $0.017 \pm 0.000$ & $0.038 \pm 0.000$ \\
Total copper $(\mathrm{mg} / \mathrm{L})$ & $0.002 \pm 0.000$ & $0.005 \pm 0.001$ & $0.002 \pm 0.000$ & $0.002 \pm 0.000$ & $0.002 \pm 0.001$ \\
Total lead $(\mathrm{mg} / \mathrm{L})$ & $0.000 \pm 0.000$ & $0.001 \pm 0.000$ & $0.000 \pm 0.000$ & $0.001 \pm 0.000$ & $0.000 \pm 0.000$ \\
Total zinc $(\mathrm{mg} / \mathrm{L})$ & $0.000 \pm 0.000$ & $0.001 \pm 0.001$ & $0.000 \pm 0.000$ & $0.000 \pm 0.000$ & $0.000 \pm 0.000$ \\
\hline
\end{tabular}

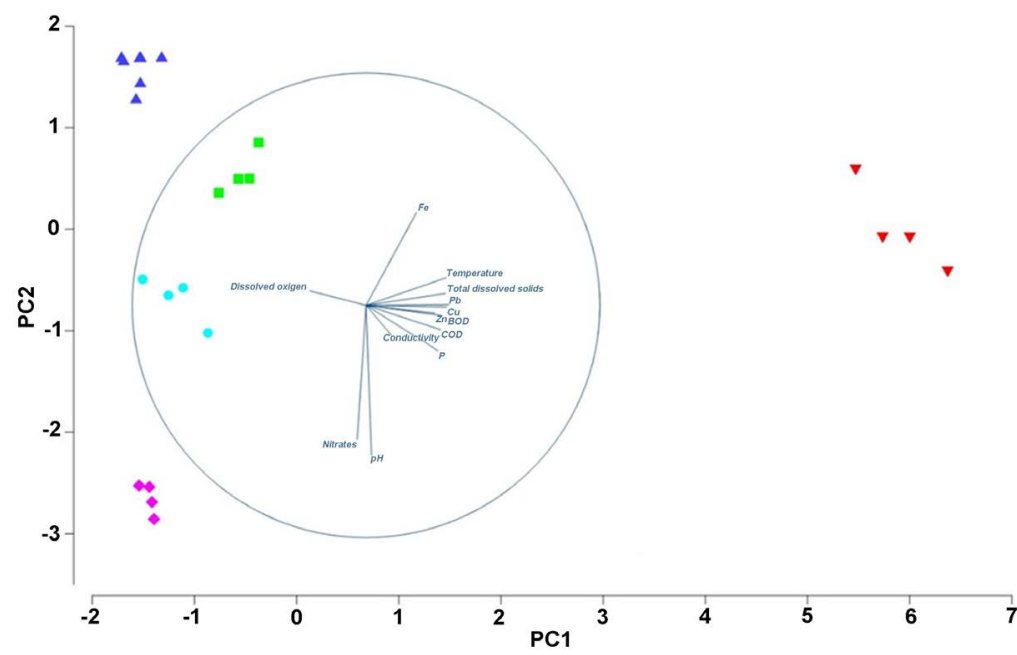

Figure 2. Perceptual map of principal component analysis (PCA) based on the normalized physicochemical indicators of central Andean lakes.

(60.1\%) correlated positively and significantly with the temperature, the concentration of total dissolved solids, lead, copper, BOD, COD and total phosphorus, and negatively with dissolved oxygen and nitrates. On the other hand, the second component (17.4\%) correlated positively and significantly with total iron and negatively with nitrate concentration and its $\mathrm{pH}$. Therefore, the first component would be indicating an anthropogenic pressure gradient, especially in $\mathrm{Tg}$ Lake, while the second component could be related to the seasonal variability of water characteristics. For example, at a level of significance of 0.05 , the $\mathrm{pH}$ 
showed a high positive correlation with nitrates ( 0.80 Pearson rank) and negative correlation with total iron $(-0.58)$, the COD correlated positively with $\mathrm{BOD}$ (0.87), temperature (0.78), total dissolved solids (0.78), total phosphorus (0.92), total copper (0.81), lead (0.84), and zinc (0.68) and, it was negatively correlated with the DO (-0.73).

\subsection{Variation Patterns of Benthic Macroinvertebrate Communities}

We counted 1307 individuals of benthic macroinvertebrates grouped in 12 taxa. According to the point of partition, at $63 \%$ similarity, the cluster analysis grouped the 23 sampling sites into three different groups. The sampling sites of Tg Lake showed a greater dissimilarity with respect to the rest of the lakes. In relation to relative abundance, the Pc, Ñn and Ic Lakes generate a cluster with a minimum similarity of 70\%, differing from the one generated by the Cc Lake at a level of similarity of $62 \%$, making the cluster analysis allow in generating a discriminating factor (Figure 3 ).

The non-metric multidimensional scaling analysis shows an average value of stress level of 0.13 that according to the range given by Kruskal indicates an acceptable interpretation in the perceptual map, since the observation would replicate the original distributions fairly. The principal coordinate analysis ( $\mathrm{PCoA})$ of the composition of the benthic macroinvertebrate communities (Figure 4), showed a clear separation of site, mainly between $\mathrm{Tg}$ and the other the lakes. The first management axis shows that Lake Tg is separated from others, which explains a large part of the total variation (41.18\%). The second management axis explained less variation (25.27\%) separating the Pc, Ic, Ñn lakes from the Cc lake. The analysis shows for the axis 1 , values that range from -36 to -23 according to the range of similarity of Bray Curtis, mainly because this grouping of samples grouped by the similarity of species denominated as group $a$, is different

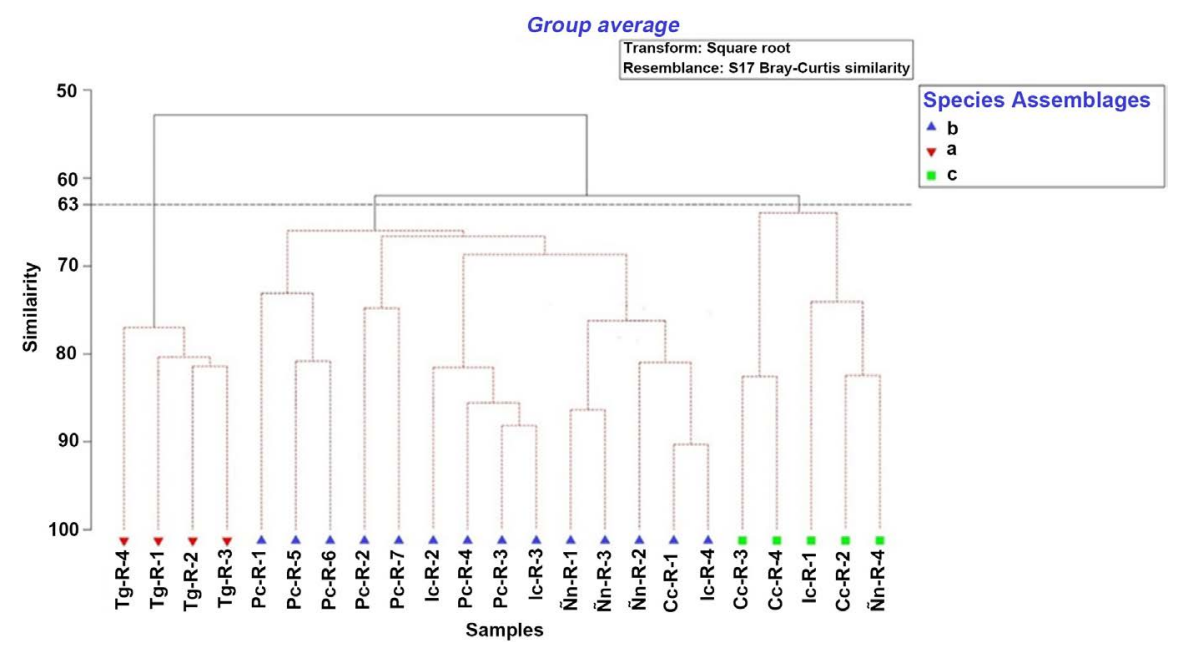

Figure 3. Dendrogram based on the relative abundance determined from 23 sampling points in the high Andean lakes. Three grouping clusters were identified at the level of $63 \%$ similarity, and were designed $a, b$ and $c$. 


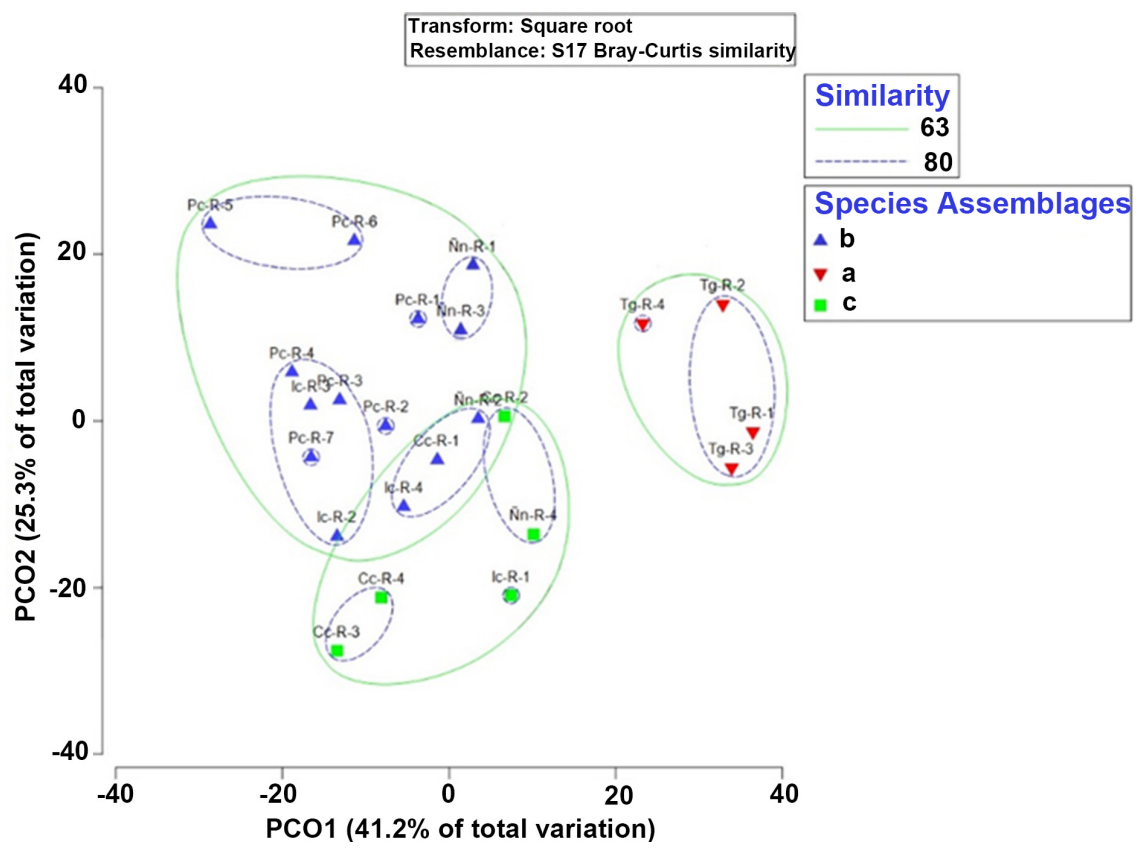

Figure 4. Principal Coordinate Analysis (PCoA) based on the number of species and abundances of benthic macroinvertebrates of the 23 sampling points, using grouping clusters as a factor of discrimination.

from the others in a significant way. The groups $b$ and $c$, have a higher similarity value but still are significantly different in relation to the number of species and abundance of macro invertebrates. The grouping of these groups is categorized by a range of similarity of $63 \%$. In addition, the PCO shows that in group a there is up to $80 \%$ similarity and in groups $b$ and $c$ with $63 \%$ similarity.

The SIMPER analysis at the family level shows the distribution of the most common species, and confirms that the clustering by the cluster analysis is addressed by the diversity indices, for example, it is observed that group $b$ is the most important in terms of diversity (Table 2). The predominant families were Chironomidae with $38.84 \%$ contribution, followed by Ceratopogonidae with $25.06 \%$ and Hydrophilidae with $18.39 \%$, with a Simpson index of 0.23 showing that it is the closest to the values of natural areas. However, the results also reveal that gaps at some point experiences anthropogenic disturbance (Figure 5). Group a, presents certain similarity with group $c$, of $62 \%$ according to the Bray-Curtis index; the difference is due to the predominance in these groups of species of the Chironomidae and Psychodidae families, in group $c$ the predominant species corresponded to the Chironomidae and Ceratopogonidae families, but they differ in the number of species and abundances. Group a, shows the poorest indexes in diversity as an effect of the anthropogenic activity that takes place in the area.

The PERMANOVA analysis of the benthic macroinvertebrates community is divided according to the factor of the groups of species, reveals that at a significance level of 0.01 , there are significant differences between the number of species and abundances of the evaluated zones; and is that at least one of the gaps 
Table 2. Indexes of diversity and percentage of contribution of families of benthic macroinvertebrate families according to the species group factor in the SIMPER analysis.

\begin{tabular}{cccccccc}
\hline Species Assemblages & Taxon & Simper & $\boldsymbol{S}$ & $\boldsymbol{N}$ & $\boldsymbol{d}$ & $\boldsymbol{H}$ & $1-\lambda$ \\
\cline { 2 - 3 } & Chironomidae & $51.23 \%$ & & & & & \\
& Psychodidae & $21.44 \%$ & 7 & 468 & 0.98 & 1.134 & 0.478 \\
& Chironomidae & $38.84 \%$ & & & & & \\
b & Ceratopogonidae & $25.06 \%$ & 11 & 635 & 1.55 & 1.768 & 0.231 \\
& Hydrophilidae & $18.39 \%$ & & & & & \\
c Chironomidae & $53.50 \%$ & & & & & \\
& Ceratopogonidae & $34.44 \%$ & 6 & 167 & 0.98 & 1.2 & 0.4 \\
\hline
\end{tabular}

$S$, number of species; $N$, number of individuals; $d$, Margalef index; $H$, Shannon index; $1-\lambda$, Simpson's index.

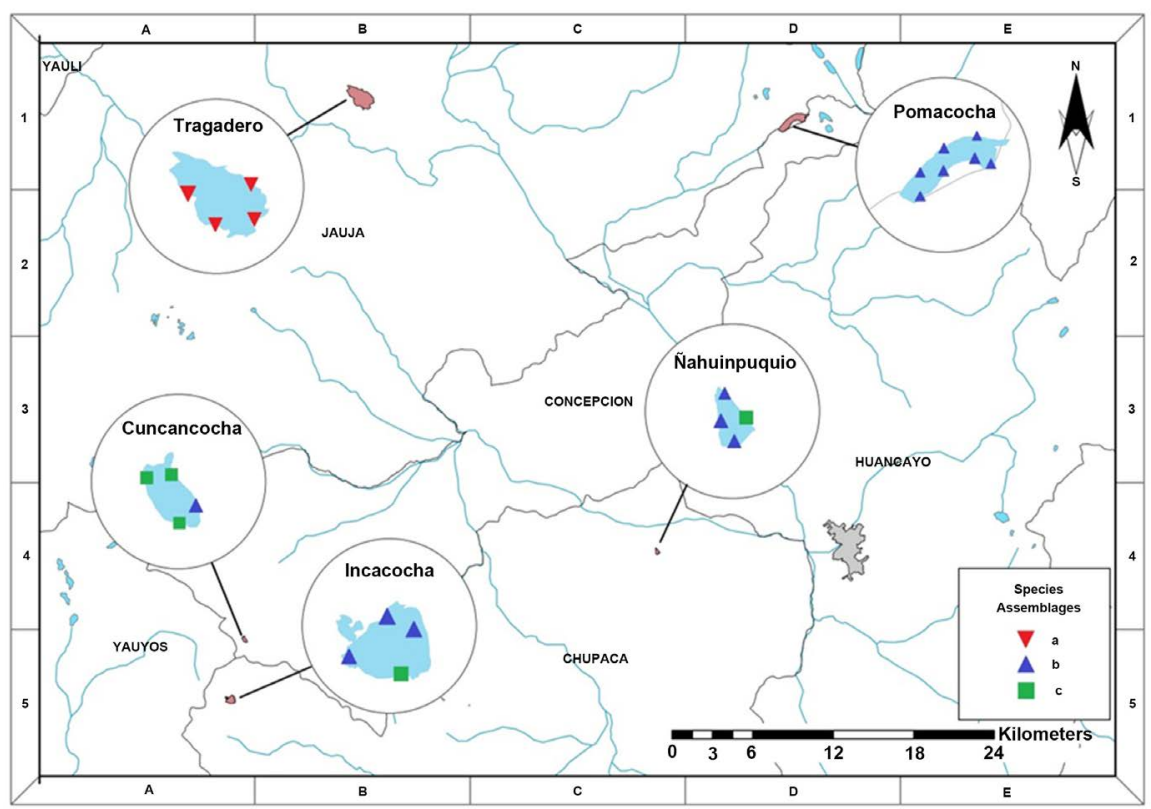

Figure 5. Geographic distribution of the three groups of species and abundances determined by the cluster analysis of the lakes.

differs from the others. In addition, using the zone of study factor in the comparison analysis of pairs, the Tg Lakes shows significant differences in comparison with the other lakes, in relation to the number of species and abundances. This difference is much more significant compared to Pc Lake, but comparing the Pc and Ic Lakes the results reveal that these are statistically similar. However, the zones with a high level of similarities are the areas of Cc, Ic and Ñn.

\subsection{Influence of Water Quality on the Variation Patterns of Benthic Macroinvertebrate Communities}

The BIOENV analysis revealed that the variations in the distribution of the benthic macroinvertebrates of the high Andean lakes can be better explained taking 
into account the 13 water quality variables considered in the study (Table 3 ). The results show that total phosphorus is the variable that has a higher correlation value with the distribution of biological data, with a $57 \%$ values in the Spearman range. Although this value was increased with the number of water quality variables combined.

We used the model based on linear distances which analyzes and models the relationship between a multivariate data cloud and one or more predictor variables, with several options for model selection. The coefficient of determination obtained allows us to understand the relationship between these data. By testing all the predictor variables, the marginal test indicates that the BOD, COD, DO, dissolved total solids, total phosphorous, iron, copper, lead and total zinc are predictors that explains the distribution of the benthic macro invertebrates at a level of significance of 0.05 . While the variables of conductivity, nitrates and $\mathrm{pH}$, do not show significant differences. The sequential test shows that the most important predictors are the BOD and the total phosphorus, since they explain with a higher proportional index to the distribution of the biological observations at 0.01 significance level. Using these two predictors, the coefficient of determination $\mathrm{R} 2$ shows a value of 0.45 , which is acceptable to reflect the goodness of fit of a model to the variable that it is intended to explain (Table 4).

The result of the redundancy-dbRDA analysis of the physicochemical variables of water and the relative abundances of benthic macroinvertebrates is presented in Figure 6. The first axis of the redundancy analysis explains $35.1 \%$ of the total variance, and the second axis $10.3 \%$. The vectors for BOD and total phosphorus reveal that these variables are strongly correlated with the abundance of benthic macroinvertebrate communities and may explain why BEST identified them as important. According to the result of the weights of the coefficients for the linear combination of axes in the formation of coordinates of the $\mathrm{dbRDA}$, the primary axis shows strong loads for the total phosphorus variable $(-7.351)$, indicating that this variables is responsible for the group $b$ of the clustering of species is significantly isolated from the other groups ( $a$ and $c$ ).

\section{Discussion}

\subsection{Water Quality Based on Physicochemical Indicators}

The results obtained from the physicochemical evaluation of the water quality of high Andean lakes reveal some deterioration, which is probably caused by the increase of anthropogenic activities as a result of the accelerated urban expansion in the region. The highest values of conductivity, COD and BOD recorded in Lake $\mathrm{Tg}$ are due to the presences of ions and anions that are concentrated due to evaporation matter in water [21]. The values of COD and BOD greatly exceeded the water quality standards for the conservation of aquatic life, the production of drinking water and its uses according to Peruvian regulations [22]. As well as the ranges established by the World Health Organization (WHO, 2011) [23] and the Canadian Council of Ministers of the Environment [24]. 
Table 3. Better correlations obtained between a growing number of physicochemical water quality variables and the distribution of benthic macroinvertebrates in the high Andean lakes, according to the BIOENV analysis.

$\left.\begin{array}{cccc}\hline \begin{array}{c}\mathrm{N}^{\bullet} \text { of } \\ \text { variables }\end{array} & \text { Correlation } & \begin{array}{c}\mathrm{p} \text {-value } \\ (\mathbf{0 . 0 5})\end{array} & \text { Selections } \\ \hline 1 & 0.574 & 0.004183 & \text { Total phosphorus }(\mathrm{mg} / \mathrm{L}) \\ 2 & 0.609 & 0.002041 & \mathrm{BOD}_{5}(\mathrm{mg} / \mathrm{L}), \text { Total phosphorus }(\mathrm{mg} / \mathrm{L}) \\ 3 & 0.611 & 0.001954 & \mathrm{COD}(\mathrm{mg} / \mathrm{L}), \mathrm{BOD}_{5}(\mathrm{mg} / \mathrm{L}), \text { Total phosphorus }(\mathrm{mg} / \mathrm{L}) \\ 4 & 0.614 & 0.00183 & \mathrm{COD}(\mathrm{mg} / \mathrm{L}), \mathrm{BOD}_{5}(\mathrm{mg} / \mathrm{L}), \text { Total phosphorus }(\mathrm{mg} / \mathrm{L}), \\ \text { Total copper }(\mathrm{mg} / \mathrm{L})\end{array}\right)$

Table 4. Hierarchical classification of variables of physicochemical water with significant influence $(\mathrm{p}<0.01)$ on the distribution of benthic macro invertebrates in the high Andean lakes, as revealed by the direct selection in the DistLm procedure with Akaike information criterion (AICc).

\begin{tabular}{|c|c|c|c|c|}
\hline \multicolumn{5}{|c|}{ MARGINAL TESTS } \\
\hline Variable & SS (trace) & Pseudo-F & p-value & Decreasing Prop. \\
\hline $\mathrm{BOD}_{5}(\mathrm{mg} / \mathrm{L})$ & 5671.3 & 10.78 & 0.001 & 0.339 \\
\hline Phosphorus total (mg/L) & 5531 & 10.382 & 0.001 & 0.331 \\
\hline Total copper $(\mathrm{mg}(\mathrm{L})$ & 5200 & 9.4801 & 0.001 & 0.311 \\
\hline Total lead (mg/L) & 5203.6 & 9.4897 & 0.001 & 0.311 \\
\hline $\mathrm{COD}(\mathrm{mg} / \mathrm{L})$ & 4821.1 & 8.51 & 0.001 & 0.288 \\
\hline Total dissolved solids (mg/L) & 4524.8 & 7.792 & 0.001 & 0.2706 \\
\hline Temperature $\left({ }^{\circ} \mathrm{C}\right)$ & 4296.4 & 7.263 & 0.001 & 0.2569 \\
\hline Total zinc $(\mathrm{mg}(\mathrm{L})$ & 4001.9 & 6.6085 & 0.001 & 0.239 \\
\hline Total iron $(\mathrm{mg} / \mathrm{L})$ & 2762.6 & 4.1569 & 0.004 & 0.165 \\
\hline Dissolved oxygen (mg/L) & 2142.2 & 3.086 & 0.017 & 0.1281 \\
\hline Conductivity $(\mathrm{S} / \mathrm{cm})$ & 1219.4 & 1.652 & 0.145 & 0.07 \\
\hline Nitrates $(\mathrm{mg} / \mathrm{L})$ & 761.49 & 1.002 & 0.395 & 0.045 \\
\hline $\mathrm{pH}$ (Unity) & 742.87 & 0.976 & 0.425 & 0.04 \\
\hline
\end{tabular}

The results obtained through the PCA reveals that the lakes which are under study have been experiencing a process of worsening water quality due to the strong anthropogenic pressure that they have been supporting. Being the Lake $\mathrm{Tg}$ that displays a quality of bad water according to COD, BOD and DO. The low $\mathrm{DO}$ concentration would be due to the consumption of this gas in the biodegradation processes, as revealed by the high concentrations of BOD registered in this lake. These results are supported by Shi et al. (2017) [8] who reported that the increase in temperature reduces the dissolution of oxygen in the aquatic environment. In addition, the low concentration of oxygen is related to the strong activity of microorganisms that require large amounts of oxygen to metabolize and degrade organic matter [25]. 


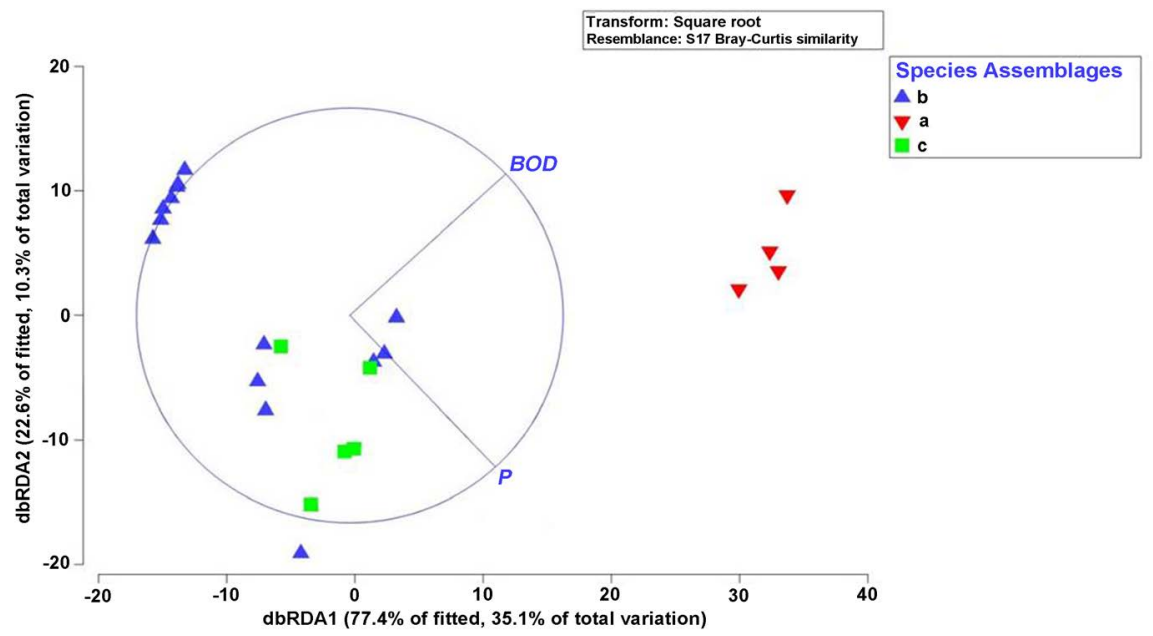

Figure 6. Perceptual map of the distance-based redundancy analysis (dbRDA) of the best physicochemical predictors of the composition of benthic macroinvertebrate communities in the lakes of the central highlands of Peru.

Temperature is one of the factors with a great importance in the development of the different processes that are carried out in water, such as the dissolution of oxygen, since it determines the tendency of its physical properties, and the richness and distribution of biological communities [26]. The temperature measured in the evaluated lakes shows small variations, although in Lake Tg, a high water temperatures were registered, which would be influencing the distribution of communities of the macroinvertebrates.

Phosphorus in aquatic environments limits the growth of algae and plants, because their determination can detect problems of eutrophication [27]. The average values of total phosphorus obtained exceed the environmental quality standards (EQS) for the conservation of the aquatic environment $(0.035 \mathrm{mg} / \mathrm{L})$. This increase would be related to the discharges of domestic wastewater and the drainage of fertilized agriculture land [28]. In the case of Lake Tg, the values found allow us to classify this body of water in a hypertrophic state with great algal blooms. In addition, these high concentrations of phosphorus reveal the contamination events through which it crosses due to the strong pressure in the aquatic environment exerted by anthropogenic activities; among them is the cattle livestock, since the feces of the cattle are potential source of phosphorus. The mean values of the nitrate concentration did not exceed the EQS in any of the gaps evaluated. Therefore, it is necessary to integrate research into these ecosystems in a way that reveals the pressure exerted by the development of anthropogenic activities in the aquatic environment and biological communities. In addition, the interaction between phosphorus and iron, at low DO concentrations, causes the release of phosphorus attached to the water column, increasing its concentrations [29].

\subsection{Variation Patterns of Benthic Macroinvertebrate Communities}

Aquatic ecosystems have been experiencing a progressive decline in their quali- 
ty, affecting the aquatic life they harbor and the services they provide. In Peru, the monitoring of water quality in these ecosystems is limited to the use of physical and chemical determinations. The entities responsible for water management have not yet considered monitoring the quality of water in an integral manner, taking into account the composition and structure of the biological communities [30]. According to experiences worldwide, the evaluation of water quality through macroinvertebrate communities has shown innumerable advantages over other biological groups [31], highlighting its cosmopolitan nature, since they are found practically in all aquatic ecosystems, which favors comparative studies; as well as its sedentary nature, which allows an effective spatial analysis of the disturbing effects.

The results obtained show that the most abundant benthic macroinvertebrates correspond to individuals of the Insecta Class, order Diptera. They also show significant differences between the macroinvertebrate communities of the evaluated lagoons, being the Chironomidae family the most common with a wide range of distribution [32]. Regarding the contribution of families of benthic macro invertebrates in the composition of the communities, the Chironomidae was determined as one of the most important families in the evaluated lakes. However, the most evident was the dominance is the families of Chironomidae, Ceratopogonidae and Hydrophilidae. The abundance of the species of these families in the Cc Lake confirms the average level of oxygenation of the water masses. Likewise, the greater abundance of these species in the Tg Lake corroborates the low level of oxygenation of its waters. These results coincide with those recorded in other studies in aquatic environments with low oxygen levels, dominance of Chironomidae and decrease in macro invertebrate density [33]. However, these effects are related to the decrease in the quality of water, food and the interference of breathing mechanisms [34]. Other families seen in the study and known for their abundances in the lakes are Psychodidae and Hydrophilidae, which are characterized by living in oligotrophic waters.

The results also indicate that each of the taxa responded differently on the environmental conditions of each lake. For example, group $b$ comprised of the families Chironomidae, Ceratopogonidae and Hydrophilidae reached the greatest abundance and diversity. However, these families are considered resistant and resilient taxa due to the anthropogenic pressure that impoverish biological communities and consequently alter aquatic ecosystems [35] [36]. These results could be related to the hydrological stability and physicochemical quality of water [37]. In addition, they coincide with the results of Verdonschot et al. (2012) [38] and [39], who indicate that in areas with a temperate climate, seasonality plays a very important role in the structure of macroinvertebrate communities.

\section{Conclusions}

This study used several multivariate statistical techniques to evaluate the influence of water quality on the variation patterns of the benthic macroinvertebrate communities in the central highlands of Peruvian lakes. The PCA reduced the 
variables to a few significant components that caused variation in water quality between the lakes. The cluster analysis in relation to the relative abundance of benthic macroinvertebrates grouped the 23 sampling sites into three groups with similar characteristics. The analysis of the main coordinates of the composition of the benthic macroinvertebrate communities showed a clear separation of sites, mainly between Tg and the other lakes. The SIMPER analysis at the family level shows the distribution of the most representative species, and confirms that grouping by cluster analysis is addressed by diversity indices.

The PERMANOVA analysis of the community of benthic macroinvertebrates divided according to the factor of groups of species reveals that at a level of significance of 0.01 there are significant differences between the number of species and abundances of the evaluated areas. The marginal test indicates that the BOD, COD, DO, total dissolved solids, total phosphorus, iron, copper, lead and total zinc are predictors that explain the distribution of the benthic macroinvertebrates at a level of significance 0.05 . The DistLm analysis according to the sequential test reveals that $\mathrm{BOD}$ and total phosphorus are the most important physical variables with a coefficient of determination of 0.45 . Therefore, these results are useful to establish a baseline for the detection of changes in ecological status and anthropogenic impacts.

\section{Words of Gratitude}

The authors express their gratitude to the General Research Institute of the Universidad Nacional del Centro del Peru for the financing of the study, to the Water Research Laboratory for allowing us to make use of the equipment and materials for this study.

\section{Conflicts of Interest}

The authors declare that they have no conflict of interest.

\section{References}

[1] Vanderhoof, M.K., Alexander, L.C. and Todd, M.J. (2016) Temporal and Spatial Patterns of Wetland Extent Influence Variability of Surface Water Connectivity in the Prairie Pothole Region, United States. Landscape Ecology, 31, 805-824.

https://doi.org/10.1007/s10980-015-0290-5

[2] Qadir, A. and Naseem, M.R. (2009) Assessment of an Index of Biological Integrity (IBI) to Quantify the Quality of Two Tributaries of river Chenab, Sialkot, Pakistan. Hidrobiologia, 621, 127-153. https://doi.org/10.1007/s10750-008-9637-0

[3] Yang, Y., Yin, X. and Yang, Z. (2016) Environmental Flow Management Strategies Based on the Integration of Water Quantity and Quality, a Case Study of the Baiyangdian Wetland, China. Ecological Engineering, 96, 150-161.

https://doi.org/10.1016/j.ecoleng.2015.12.018

[4] Alam, M.Z., Carpenter-Boggs, L., Rahman, A., Haque, M.M., Miah, M.R.U., Moniruzzaman, M., Abdullah, H.M., et al. (2016) Water Quality and Resident Perceptions of Declining Ecosystem Services at Shitalakka Wetland in Narayanganj City. Sustainability of Water Quality and Ecology, 9-10, 53-66. 
[5] Sierra, C.A., Mahecha, M., Poveda, G., Álvarez-Dávila, E., Gutierrez-Velez, V.H., Reu, B., Skowronek, S., et al. (2017) Monitoring Ecological Change during Rapid Socio-Economic and Political Transitions: Colombian Ecosystems in the Post-Conflict Era. Environmental Science and Policy, 76, 40-49. https://doi.org/10.1016/j.envsci.2017.06.011

[6] Eda, L.E.H. and Chen, W. (2010) Integrated Water Resources Management in Peru. Procedia Environmental Sciences, 2, 340-348. https://doi.org/10.1016/j.proenv.2010.10.039

[7] Živić, I., Živić, M., Milošević, D., Bjelanović, K., Stanojlović, S., Daljević, R. and Marković, Z. (2013) The Effects of Geothermal Water Inflow on Longitudinal Changes in Benthic Macroinvertebrate Community Composition of a Temperate Stream. Journal of Thermal Biology, 38, 255-263.

https://doi.org/10.1016/j.jtherbio.2013.03.005

[8] Shi, X., Liu, J., You, X., Bao, K., Meng, B. and Chen, B. (2017) Evaluation of River Habitat Integrity Based on Benthic Macroinvertebrate-Based Multi-Metric Model. Ecological Modelling, 353, 63-76. https://doi.org/10.1016/j.ecolmodel.2016.07.001

[9] Petus, C., Marieu, V., Novoa, S., Chust, G., Bruneau, N. and Froidefond, J.M. (2014) Monitoring Spatio-Temporal Variability of the Adour River Turbid Plume (Bay of Biscay, France) with MODIS 250-m Imagery. Continental Shelf Research, 74, 35-49. https://doi.org/10.1016/j.csr.2013.11.011

[10] Nguyen, H.H., Everaert, G., Gabriels, W., Hoang, T.H. and Goethals, P.L.M. (2014) A Multimetric Macroinvertebrate Index for Assessing the Water Quality of the Cau River Basin in Vietnam. Limnologica, 45, 16-23. https://doi.org/10.1016/j.limno.2013.10.001

[11] Van Ael, E., De Cooman, W., Blust, R. and Bervoets, L. (2015) Use of a Macroinvertebrate Based Biotic Index to Estimate Critical Metal Concentrations for Good Ecological Water Quality. Chemosphere, 119, 138-144. https://doi.org/10.1016/j.chemosphere.2014.06.001

[12] APHA/AWWA/WEF (2012) Standard Methods for the Examination of Water and Wastewater. Standard Methods, 541.

[13] Huamantinco, A. and Ortiz, W. (2010) Key of Genera of larvae of Trichoptera (Insecta) of the Western Slope of the Andes, Lima, Peru. Revista Peruana de Biología, 17, 75-80.

[14] Dutertre, M., Hamon, D., Chevalier, C. and Ehrhold, A. (2013) The Use of the Relationships between Environmental Factors and Benthic Macrofaunal Distribution in the Establishment of a Baseline for Coastal Management. ICES Journal of Marine Science, 70, 294-308. https://doi.org/10.1093/icesjms/fss170

[15] Ceschia, C., Falace, A. and Warwick, R. (2007) Biodiversity Evaluation of the Macroalgal Flora of the Gulf of Trieste (Northern Adriatic Sea) Using Taxonomic Distinctness Indices. Hydrobiologia, 580, 43-56.

https://doi.org/10.1007/s10750-006-0466-8

[16] Padovan, A., Munksgaard, N., Alvarez, B., McGuinness, K., Parry, D. and Gibb, K. (2012) Trace Metal Concentrations in the Tropical Sponge Spheciospongia vagabunda at a Sewage Outfall: Synchrotron X-Ray Imaging Reveals the Micron-Scale Distribution of Accumulated Metals. Hydrobiologia, 687, 275-288.

https://doi.org/10.1007/s10750-011-0916-9

[17] Beyer, S., Kinnear, A., Hutley, L.B., McGuinness, K. and Gibb, K. (2011) Assessing the Relationship between Fire and Grazing on Soil Characteristics and Mite Communities in a Semi-Arid Savanna of Northern Australia. Pedobiologia, 54, 195-200. 
https://doi.org/10.1016/j.pedobi.2011.03.002

[18] Anderson, M.J. and Willis, T.J. (2003) Canonical Analysis of Principal Coordinates: A Useful Method of Constrained Ordination for Ecology. Ecology, 84, 511-525. https://doi.org/10.1890/0012-9658(2003)084[0511:CAOPCA]2.0.CO;2

[19] Primo, A.L., Marques, S.C., Falcão, J., Crespo, D., Pardal, M.A. and Azeiteiro, U.M. (2012) Environmental Forcing on Jellyfish Communities in a Small Temperate Estuary. Marine Environmental Research, 79, 152-159. https://doi.org/10.1016/j.marenvres.2012.06.009

[20] Yergeau, E., Schoondermark-Stolk, S.A., Brodie, E.L., Déjean, S., Desantis, T.Z., Gonçalves, O., Kowalchuk, G.A., et al. (2009) Environmental Microarray Analyses of Antarctic Soil Microbial Communities. The ISME Journal, 3111, 340-351. https://doi.org/10.1038/ismej.2008.111

[21] Effendi, H. (2016) Evaluation of Water Quality Status of Ciliwung River Based on Pollution Index. 11-14.

[22] MINEN (2015) Supreme Decree No. 015-2015-MINEN-National Environmental Quality Standards for Water. Official Newspaper El Peruano 3.

[23] WHO (2011) Guidelines for Drinking-Water Quality. Fourth Edition.

[24] Canadian Council of Ministers of the Environment (CMME) (2007) Canadian Water Quality Guidelines for the Protection of Aquatic Life. Canadian Water Quality Guidelines.

[25] Hoyle, G.M., Holderman, C., Anders, P.J., Sha, B. and Ashley, K.I. (2014) Water Quality, Chlorophyll, and Periphyton Responses to Nutrient Addition in the Kootenai River. Idaho, 33, 1024-1029.

[26] Seiler, L.M.N., Helena, E., Fernandes, L., Martins, F. and Cesar, P. (2015) Evaluation of Hydrologic Influence on Water Quality Variation in a Coastal Lagoon through Numerical Modeling. Ecological Modelling, 314, 44-61.

https://doi.org/10.1016/j.ecolmodel.2015.07.021

[27] Cony, N.L., Ferrer, N.C. and Cáceres, E.J. (2016) Evolution of the Trophic State and Phytoplankton Structure of a Somero Lake in the Pampean Region: Laguna Sauce Grande. (Pcia. De Buenos Aires, Argentina). Biología Acuática, 30, 79-91.

[28] Barakat, A., El Baghdadi, M., Rais, J., Aghezzaf, B. and Slassi, M. (2016) Assessment of Spatial and Seasonal Water Quality Variation of Oum Er Rbia River (Morocco) Using Multivariate Statistical Techniques. International Soil and Water Conservation Research, 4, 284-292. https://doi.org/10.1016/j.iswcr.2016.11.002

[29] Paudel, B., Weston, N., O’Connor, J., Sutter, L. and Velinsky, D. (2017) Phosphorus Dynamics in the Water Column and Sediments of Barnegat Bay, New Jersey. Journal of Coastal Research, 78, 60-69. https://doi.org/10.2112/SI78-006.1

[30] Chowdhury, G.W., Gallardo, B. and Aldridge, D.C. (2015) Development and Testing of a Biotic Index to Assess the Ecological Quality of Lakes in Bangladesh. $\mathrm{Hy}^{-}$ drobiologia, 765, 55-69.

[31] White, J.C., House, A., Punchard, N., Hannah, D.M., Wilding, N.A. and Wood, P.J. (2018) Macroinvertebrate Community Responses to Hydrological Controls and Groundwater Abstraction Effects across Intermittent and Perennial Headwater Streams. Science of the Total Environment, 610-611, 1514-1526. https://doi.org/10.1016/j.scitotenv.2017.06.081

[32] Vamosi, S., Silver, C.A. and Vamosi, S.M. (2012) Macroinvertebrate Community Composition of Temporary Prairie Wetlands: A Preliminary Test of the Effect of ... Macroinvertebrate Community Composition of Temporary Prairie Wetlands: A 
Preliminary Test of the Effect of Rotational Grazing. Wetlands, 32, 185-197. https://doi.org/10.1007/s13157-012-0268-X

[33] Riens, J.R., Schwarz, M.S. and Hoback, W.W. (2013) Aquatic Macroinvertebrate Communities and Water Quality at Buffered and Non-Buffered Wetland Sites on Federal Waterfowl Production Areas in the Rainwater Basin, Nebraska Aquatic Macroinvertebrate Communities and Water.

[34] Miserendino, M.L., Archangelsky, M., Brand, C. and Epele, L.B. (2012) Environmental Changes and Macroinvertebrate Responses in Patagonian Streams (Argentina) to Ashfall from the Chaitén Volcano (May 2008). Science of the Total Environment, 424, 202-212. https://doi.org/10.1016/j.scitotenv.2012.02.054

[35] Sharma, R.C. and Rawat, J.S. (2009) Monitoring of Aquatic Macroinvertebrates as Bioindicator for Assessing the Health of Wetlands: A Case Study in the Central Himalayas, India. Ecological Indicators, 9, 118-128.

https://doi.org/10.1016/j.ecolind.2008.02.004

[36] Nkwoji, J.A., Ajani, G. and Yakub, A.S. (2010) Seasonal Variations in the Water Chemistry and Benthic Macroinvertebrates of a South Western Lagoon, Lagos, Nigeria. Journal of American Science, 6, 9.

[37] Sharifinia, M., Mahmoudifard, A., Imanpour Namin, J., Ramezanpour, Z. and Yap, C.K. (2016) Pollution Evaluation in the Shahrood River: Do Physico-Chemical and Macroinvertebrate-Based Indices Indicate Same Responses to Anthropogenic Activities? Chemosphere, 159, 584-594.

https://doi.org/10.1016/j.chemosphere.2016.06.064

[38] Verdonschot, R.C.M., Didderen, K. and Verdonschot, P.F.M. (2012) Importance of Habitat Structure as a Determinant of the Taxonomic and Functional Composition of Lentic Macroinvertebrate Assemblages. Limnologica Ecology and Management of Inland Waters, 42, 31-42. https://doi.org/10.1016/j.limno.2011.07.004

[39] Mykrä, H., Saarinen, T., Tolkkinen, M., McFarland, B., Hämäläinen, H., Martinmäki, K. and Kløve, B. (2012) Spatial and Temporal Variability of Diatom and Macroinvertebrate Communities: How Representative Are Ecological Classifications within a River System? Ecological Indicators, 18, 208-217.

https://doi.org/10.1016/j.ecolind.2011.11.007 